\title{
CYTOLOGIC PATTERNS OF LUNG CANCER
}

\author{
Prabha Raj R. L1, Priya P. V', Sankar $S^{3}$
}

1 Resident, Department of Pathology, Government Medical College, Kottayam.

${ }^{2}$ Associate Professor, Department of Pathology, Government Medical College, Kottayam.

3 Professor and HOD, Department of Pathology, Government Medical College, Kottayam.

\section{BACKGROUND}

ABSTRACT

Lung cancer is the most common cancer in the world today and the most common cause of cancer death in developing countries. The symptoms of lung cancer are often subtle and the diagnosis in about $70 \%$ of cases is made when metastases have occurred. Curative surgical treatment is therefore possible only in about a third of the cases, while other patients receive chemotherapy and radiation therapy. Although clinical data, location and radiological findings can narrow down the diagnostic possibilities, a definitive diagnosis confirming lung cancer by microscopic examination is indicated before therapy. In clinically suspected cases of lung cancer, if histologic confirmation is not there, cytologic confirmation is suffice. Pulmonary cytology has reached a high level of accuracy in diagnosing various subtypes of lung carcinomas. Major types of cytological preparations for diagnosing lung cancer are sputum, pleural fluid, bronchial washing/ brushing, bronchoalveolar lavage (BAL) and fine needle aspirations (FNAB) from lung lesion/ lymph nodes. Percutaneous CT-guided transthoracic fine needle aspiration cytology (TTFNA) is a well-established diagnostic method used in cytological evaluation. It must be emphasised that cytological diagnosis of lung cancer is a clinicopathological interpretation and correlation with clinical and radiographic findings is mandatory.

The present study was conducted to assess the cytological patterns of lung cancer.

\section{MATERIALS AND METHODS}

A descriptive study was done to analyse the cytomorphological patterns of carcinoma lung in 50 cytologically diagnosed cases of lung carcinoma in Department of Pathology, Government Medical College, Kottayam during a period of 15 months (July 2015 to October 2016).

\section{RESULTS}

$75 \%$ of study material was CT-guided FNA from lung lesion. Among the 50 cases of lung carcinoma studied, $28 \%$ cases were adenocarcinoma and 58\% of adenocarcinoma were peripherally located. $22 \%$ cases were squamous cell carcinoma and $90 \%$ of squamous cell carcinoma were centrally located. 14\%, 2\%, 4\% and 14\% of lung cancers were contributed by small cell carcinoma, pleomorphic carcinoma, large cell carcinoma and poorly differentiated carcinoma respectively.

\section{CONCLUSION}

Commonest cytomorphological subtype of lung cancer is adenocarcinoma. CT-guided FNA can be used as an investigation modality in cases of carcinoma lung, so thoracotomy for diagnostic purposes can be avoided.

\section{KEYWORDS}

Lung Cancer, Fine Needle Aspiration Cytology, Adenocarcinoma, Squamous Cell Carcinoma, Small Cell Carcinoma, Large Cell Carcinoma, Radiology, Papanicolaou Staining, Giemsa Staining.

HOW TO CITE THIS ARTICLE: Raj PRL, Priya PV, Sankar S. Cytologic patterns of lung cancer. J. Evolution Med. Dent. Sci. 2017;6(92):6625-6629, DOI: $10.14260 /$ jemds/2017/1436

\section{BACKGROUND}

Primary lung carcinoma is the most common carcinoma in the world today, comprising $12.6 \%$ of all the cancers and $17.8 \%$ of all the cancer deaths.

The aetiology of lung carcinoma appears to be multifactorial with both environmental and genetic conditions playing a role. Majority of lung cancer cases are believed to be related to tobacco smoking $(80 \%-90 \%)$ and also several studies reveal that tobacco smoking is the major risk factor for lung cancer in most human populations.

'Financial or Other Competing Interest': None.

Submission 12-10-2017, Peer Review 17-11-2017,

Acceptance 23-11-2017, Published 04-12-2017.

Corresponding Author:

Dr. Priya P. $V$,

Associate Professor,

Department of Pathology,

Government Medical College, Kottayam.

E-mail: pvpriya@yahoo.com

DOI: $10.14260 /$ jemds $/ 2017 / 1436$ demonstrated in epidemiological studies conducted during the 1950s in the United States and United Kingdom. Lung cancer incidence and mortality are a reflection of populationlevel changes in smoking behaviour including dose, duration and type of tobacco used. Duration of smoking is the strongest determinant of risk, but this also increases in proportion to the number of cigarettes smoked. An important aspect of tobacco-related lung carcinogenesis is the effect of cessation of smoking. The excess risk sharply decreases in exsmokers after approximately 5 years since quitting. Though smoking cessation reduces the elevated risk of lung cancer, former smokers remain at elevated risk relative to never smokers. A stronger carcinogenic effect of cigarettes than of cigars and pipe in some studies, might arise due to different inhalation patterns or composition of cigars. Recent reports suggest that smoking females are more susceptible than males.

The case fatality is high with lung cancer. Lung cancer is more prevalent in developed countries than in developing 
countries as it accounts for $22 \%$ versus $14.6 \%$ of cancer deaths, respectively. It is also the leading cause of cancerrelated death accounting for $32 \%$ of all cancer deaths in males and $25 \%$ in females. It is noteworthy that despite the link between smoking and lung cancer which was published in epidemiological studies over 60 years ago, lung cancer remains biggest cause of potentially avoidable cancer death. So these data emphasise the dominance of lung cancer as a major public health problem and underscore the need for strategies beyond smoking cessation to reduce the toll.

Several occupational agents as lung carcinogens is well established in reports dating back to the 1950s. Most important occupational lung carcinogens by the International Agency for Research on Cancer (IARC) include asbestos, silica, soot, radon, coal tar, arsenic, heavy metals, polycyclic aromatic hydrocarbons, cadmium and chromium compounds. Welding and painting were consistently associated with increased risk of lung cancer. Although, small compared with cigarette smoking, an association between lung cancer and particulate air pollution was observed. Increased mortality was associated with sulfate and fine particulate air pollution, although other unmeasured correlation of pollution cannot be excluded with certainty.

Usual clinical manifestations of carcinoma lung are progressive dyspnoea, cough, chest pain, haemoptysis and lymphadenopathy. Haemoptysis occurs mostly with squamous cell carcinoma. Pneumonia is one of the presenting features in many patients. Adenocarcinoma is more often asymptomatic and is usually identified in screening studies or as an incidental radiologic finding. Small cell lung cancer (SCLC) often presents with symptoms related to distant metastases.

Lung cancer can also present as paraneoplastic syndromes like clubbing, hypertrophic pulmonary osteoarthropathy, myasthenic syndromes, hypercalcaemia, hyponatraemia, Cushing's syndrome and carcinoid syndromes and are less common in adenocarcinoma than in other histologic types. About $15 \%$ of SCLCs produce antidiuretic hormone causing inappropriate ADH syndrome or Schwartz-Bartter syndrome leading to water retention with oedema. The patients feel clumsy, tired and weak and the plasma sodium is low and this is associated with a bad prognosis. Cerebrospinal metastases or meningeal seeding may cause neurological symptoms. Neurological symptoms may also be a paraneoplastic phenomenon. In some cases, these may be the presenting complaints. They may also be the initial sign of relapse from remission. A specific example is the Lambert-Eaton myasthenic syndrome characterised by proximal muscular weakness that improves with continued use and hyporeflexia and dysautonomia. Characteristic electromyographic findings confirm the diagnosis. This syndrome may also occur months before the primary tumour is diagnosed. Hypercalcaemia is almost pathognomonic for squamous cell carcinoma. Effusions in lung cancer patients can be benign due to obstructive pneumonia or malignant due to pleural metastases, often characterised by pleural nodularity. Such an effusion renders the tumour unresectable, though this should be confirmed by thoracocentesis or pleural biopsy. Imaging modalities for detection of lung cancer are chest x-ray, CT chest and MRI thorax. In chest radiograph, lung cancer may present as a straight forward spiculated mass, but should be suspicious in case of an unresolving pneumonia or lobar collapse. However, CT scanning of the chest is often needed, because of the lack of sensitivity of the chest radiographs in detecting mediastinal lymph node metastases and chest wall and mediastinal invasion. High-resolution computed tomography scanning further refines this. Spiral or helical CT is advantageous, as small nodules are not missed between slices. It also increases the detection rate of nodules $<5 \mathrm{~mm}$ in diameter.

The survival from bronchogenic carcinoma depends highly upon the stage at the time of diagnosis. The most important predictor of outcome in the majority of patients with lung cancer limited to the chest is the presence or absence of involvement of mediastinal lymph nodes.

The problem presented to medical profession has been to find a practical means of detecting lung cancer, while still it is at an early stage. The symptoms of lung cancer are often subtle and the diagnosis in about $70 \%$ of cases is made when metastases have occurred. Curative surgical treatment is therefore possible only in about a third of the cases, while other patients receive chemotherapy and radiation therapy. Although clinical data, location and radiological findings can narrow down the diagnostic possibilities, a definitive diagnosis confirming lung cancer by microscopic examination is indicated before therapy.

In clinically suspected cases of lung cancer, if histologic confirmation is not there, cytologic confirmation is suffice. Major types of cytological preparations for diagnosing lung cancer are sputum, pleural fluid, bronchial washing/ brushing, bronchoalveolar lavage (BAL) and fine needle aspirations (FNAB) from lung lesion/ lymph nodes. Percutaneous CT-guided transthoracic fine needle aspiration cytology (TTFNA) is a well-established diagnostic method used in cytological evaluation.

Currently, TTFNA for lesions of the lungs is a widely practiced method and is a safe and rapid method for accurate diagnosis. FNA provides a safe, simple and rapid method for accurate diagnosis in patients having mass lesions. In lung cancers, which are inoperable due to local factors or the patient's general condition, FNAC confirm the diagnosis and reveals the tumour type.

Cytological evaluation provides a very simple, cheap and rapid method to arrive at a diagnosis and thus an early treatment. It must be emphasised that cytological diagnosis of lung cancer is a clinicopathological interpretation and correlation with clinical and radiographic findings is mandatory. The purpose of the present study was to know the cytological patterns of lung cancers and to assess the clinical and radiological findings in various subtypes of lung cancer.

\section{MATERIALS AND METHODS \\ Type of Study}

Descriptive study.

\section{Study Period}

15 months (July 2015 to October 2016)

\section{Study Setting}

Department of Pathology, Government Medical College, Kottayam. 


\section{Sample Size}

Sample size was taken conveniently.

\section{Inclusion Criteria}

Cytologically diagnosed cases of lung carcinoma.

\section{Exclusion Criteria}

Cases with cytologically insufficient material, cases without proper data and cases whose radiology was not available were excluded.

\section{Study Procedure}

Study material is collected in cytology lab from the clinically suspected lung carcinoma patients. Study materials may be sputum, FOB wash, FNA from lymph node, image guided FNA from lung lesion or pleural fluid. Relevant clinical data and radiological findings were collected by using a proforma, after getting informed consent from the patient at the time of collection of study material. Fixation of study material is done by two methods- air drying and using 85\% isopropyl alcohol. The smears are stained- Papanicolaou and Giemsa method, and visualised under microscope in scanner, low-power and high-power field. Cytological pattern of the samples are identified.

\section{Data Management and Analysis}

The data was entered in Microsoft Excel and further statistical analysis was done using available institutional software.

\section{RESULTS}

$75 \%$ of study material was CT-guided FNA from lung lesion. The study population showed a peak incidence in the age group of 60 - 69 years. Majority of patients were males with a male-to-female ratio of 15: 1 . Dust exposure, smoking and alcoholism were present in $66 \%, 90 \%$ and $26 \%$ of patients respectively. Cough was the commonest symptom $(64 \%$ of cases). Mediastinal and supraclavicular lymphadenopathy were observed in $57 \%$ and $5 \%$ of cases respectively. Radiological evidence of metastasis to liver was present in $12 \%$ of cases. $56 \%$ of cases showed right lung lesion. $56 \%$ of cases showed upper lobe lesion. 22\%, 28\%, 14\%, 2\%, 4\% and $14 \%$ of lung cancers were contributed by squamous cell carcinoma, adenocarcinoma, small cell carcinoma, pleomorphic carcinoma, large cell carcinoma and poorly differentiated carcinoma respectively. $90 \%$ of squamous cell carcinoma were centrally located and $36 \%$ of squamous cell carcinoma showed cavitatory lesion. 58\% of adenocarcinoma were peripherally located lung lesions, $86 \%$ of small cell carcinoma were central lesions. Squamous cell carcinoma shows a significant association with the habit of alcoholism.

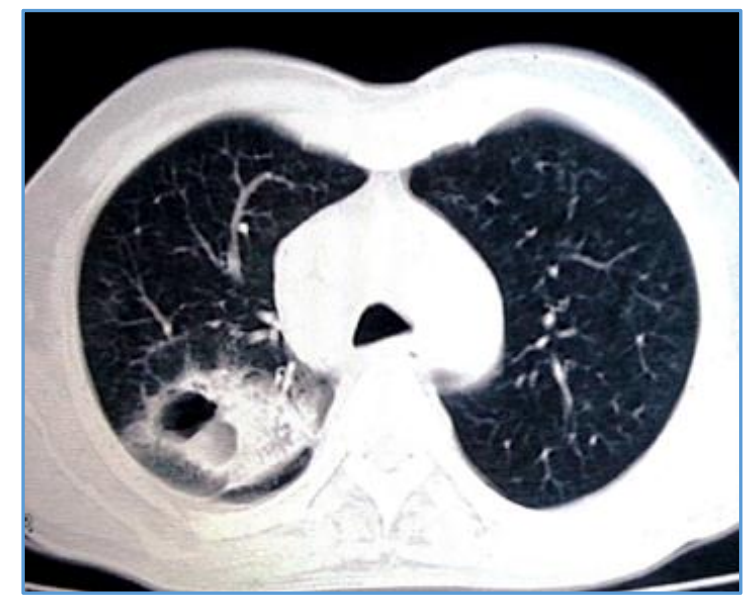

Figure 1. CT Showing Cavitatory Lesion in Right Lung

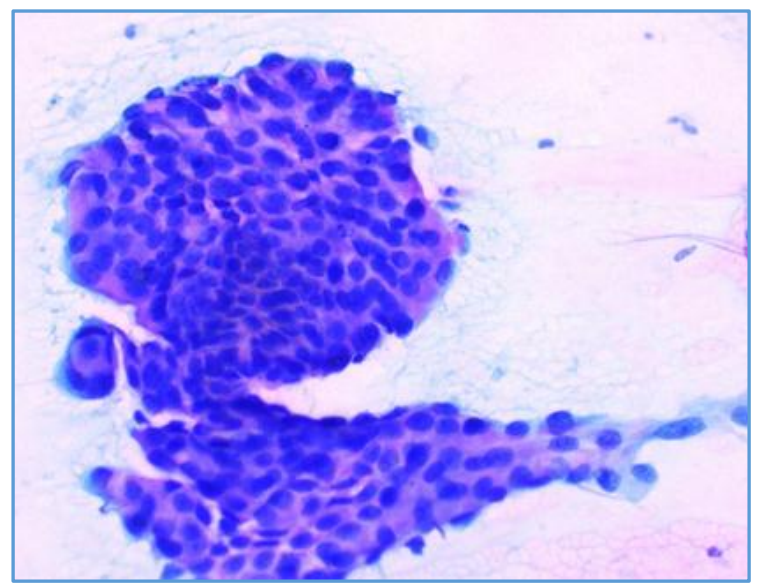

Figure 2. Cytology Smear of Adenocarcinoma showing Cells arranged in 3D Clusters (Papanicolaou Stain, 20x)

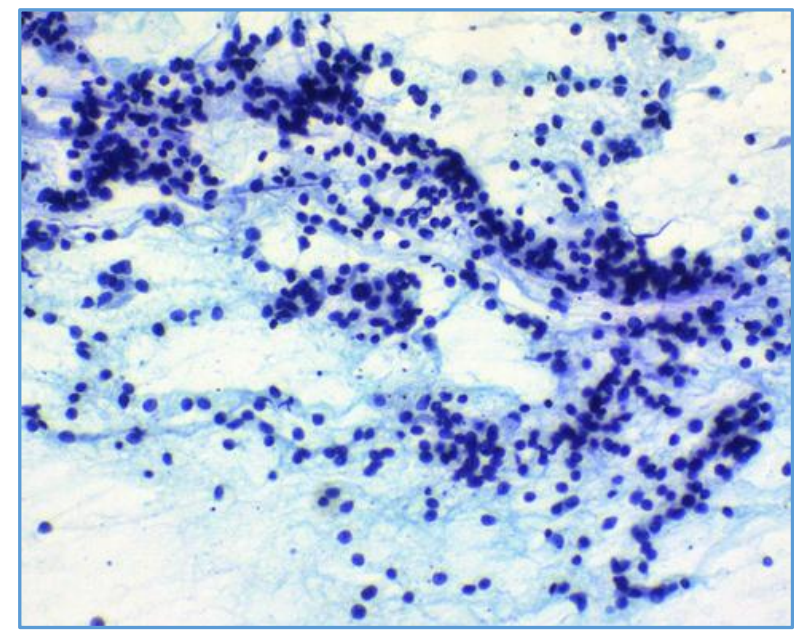

Figure 3. Cytology Smear showing Small Cell Carcinoma Lung (Papanicolaou Stain, 10x) 


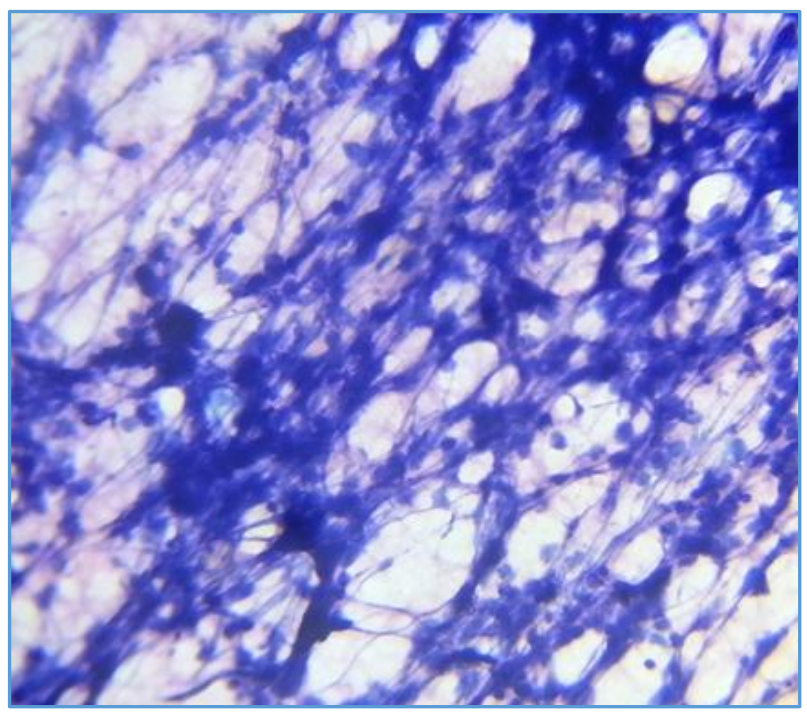

Figure 4. Cytology Smear showing Streaking Artifact in Small Cell Carcinoma Lung (Papanicolaou Stain, 20x)

\section{DISCUSSION}

Primary lung carcinoma is the most common carcinoma in the world today. Pulmonary cytology has reached a high level of accuracy in diagnosing various subtypes of lung carcinomas. Cytological diagnosis of lung cancer is a clinicopathological interpretation and correlation with clinical and radiographic findings is mandatory.

The present study was conducted on 50 cytologically diagnosed cases of lung carcinoma at Department of Pathology, Government Medical College, Kottayam between July 2015 to October 2016. The mean age group in the

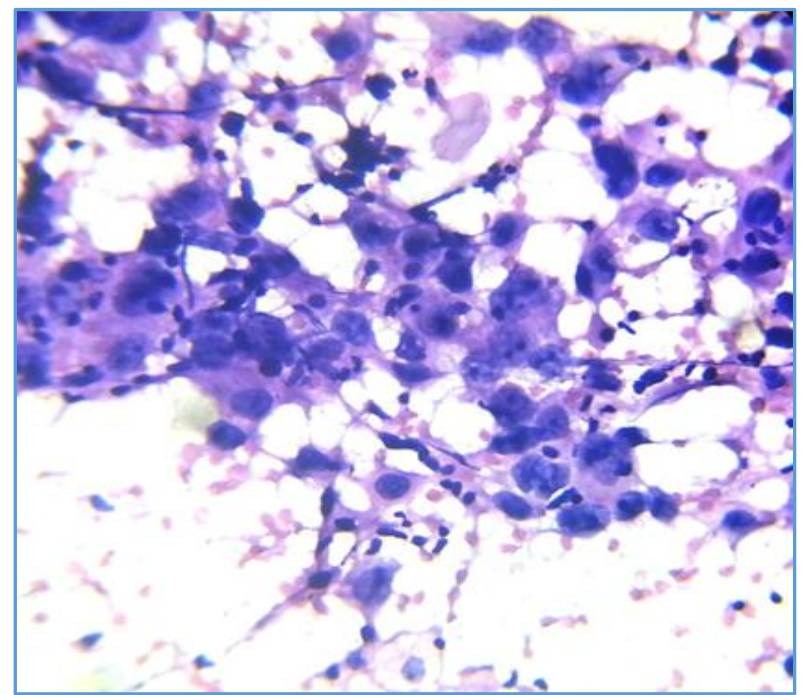

Figure 5. Cytology Smear showing Large and Bizarre Cells in Large Cell Carcinoma Lung (Papanicolaou Stain, 40x)

present study was 60 - 69 years. This finding was correlating with the studies by Mimi Gangopadhyay et $\mathrm{al}^{1}$ which showed a mean age group of $60-69$ years and Sanjay Piplani et al ${ }^{2}$ which showed an age group of 50 - 59 years. In this study in all age group males outnumbered females, constituting a total of $94 \%$. Male: Female ratio in the present study is 15: 1 . According to Mitul B Modi et al, 3 the ratio is 3: 1 . Considering the habit of smoking, in the present study, $90 \%$ of the cases had the habit of smoking. A similar finding was observed by the study of Mimi Gangopadhyay ${ }^{1}$ et al.

\begin{tabular}{|c|c|c|c|c|c|}
\hline & Present Study & Mitul B Modi et al ${ }^{1}$ & Sanjay Piplani et al ${ }^{2}$ & Santhosh Kumar Mondal et al ${ }^{4}$ & $\begin{array}{c}\text { Mimi } \\
\text { Gangopadhyay et al1 }\end{array}$ \\
\hline Smokers & $90 \%$ & $64.2 \%$ & $43.2 \%$ & $56.45 \%$ & $81 \%$ \\
\hline
\end{tabular}

$64 \%$ of patients presented with cough, $62 \%$ with dyspnoea, $36 \%$ with haemoptysis, $26 \%$ with pleuritic chest pain and $8 \%$ cases had features of metastasis as initial presentation.

In the present study, $56 \%$ of the lung cancers developed in the right lung. Previously in 2013, study by Santhosh Kumar Mondal et $\mathrm{al}^{4}$ observed that $58.06 \%$ of lung cancers developed in the right lung.
In the present study adenocarcinoma was the most common subtype of lung cancer, comprised of $28 \%$. Second most common subtype was squamous cell carcinoma that comprised of $22 \%$ and this is in accordance with the studies conducted by Santhosh Kumar Mondal et $\mathrm{al}^{4}$ and Shivani Kalhan et $\mathrm{al}^{5}$ where it comprised of $35 \%$ and $29 \%$ respectively. In the present study, small cell carcinoma comprised of $14 \%$ and this is in accordance with the study conducted by Santhosh Kumar Mondal et al ${ }^{4}$ where small cell carcinoma comprised of $16 \%$.

\begin{tabular}{|c|c|c|c|c|c|c|}
\hline & $\begin{array}{l}\text { Present } \\
\text { Study }\end{array}$ & $\begin{array}{c}\text { Mitul B Modi } \\
\text { et al }{ }^{3} \\
(n=70)\end{array}$ & $\begin{array}{c}\text { Sanjay } \\
\text { Piplani et al2 }^{2} \\
(\mathrm{n}=74)\end{array}$ & $\begin{array}{l}\text { Shivani } \\
\text { Kalhan } \\
\text { et al5 } \\
(n=98)\end{array}$ & $\begin{array}{c}\text { Santhosh Kumar } \\
\text { Mondal } \\
\text { et } \mathrm{al}^{4}(n=124)\end{array}$ & $\begin{array}{c}\text { Mimi } \\
\text { Gangopadhyay } \\
\text { et } \text { al }^{1}(n=127)\end{array}$ \\
\hline Year & 2016 & 2016 & 2014 & 2012 & 2013 & 2011 \\
\hline Adenocarcinoma & $28 \%$ & $65 \%$ & $48 \%$ & $35 \%$ & $57 \%$ & $61 \%$ \\
\hline Squamous cell carcinoma & $22 \%$ & $15 \%$ & $40 \%$ & $29 \%$ & $24 \%$ & $28 \%$ \\
\hline Small cell carcinoma & $14 \%$ & $6 \%$ & $8 \%$ & $8 \%$ & $16 \%$ & $9 \%$ \\
\hline $\begin{array}{c}\text { Poorly differentiated } \\
\text { adenocarcinoma }\end{array}$ & $10 \%$ & 0 & 0 & $11 \%$ & 0 & 0 \\
\hline $\begin{array}{c}\text { Poorly differentiated squamous } \\
\text { cell carcinoma }\end{array}$ & $2 \%$ & 0 & 0 & 0 & 0 & 0 \\
\hline $\begin{array}{l}\text { Adenocarcinoma with } \\
\text { pleomorphic component }\end{array}$ & $2 \%$ & $4 \%$ & 0 & 0 & 0 & 0 \\
\hline Poorly differentiated small cell Ca & $2 \%$ & 0 & 0 & 0 & 0 & 0 \\
\hline
\end{tabular}




\begin{tabular}{|c|c|c|c|c|c|c|}
\hline Large cell carcinoma & $4 \%$ & 0 & $4 \%$ & $1 \%$ & $2 \%$ & $2 \%$ \\
\hline Pleomorphic carcinoma & $2 \%$ & 0 & 0 & 0 & $1 \%$ & 0 \\
\hline Poorly differentiated Ca & $14 \%$ & $10 \%$ & 0 & $16 \%$ & 0 & 0 \\
\hline \\
Table 2. Comparison of Cytological Diagnosis of Carcinoma Lung \\
\hline
\end{tabular}

In the present study, $90 \%$ of squamous cell carcinoma were central lesions, $36 \%$ of which showed cavitation. $58 \%$ of adenocarcinoma were peripherally located and $86 \%$ of small cell carcinoma were central lesions. All cases of large cell carcinoma $(n=2)$ and pleomorphic carcinoma $(n=1)$ were peripheral lung lesions.

\section{Radiological Evidence of Metastasis to Liver was observed in $\mathbf{1 2} \%$ of Cases}

In the present study, among those who had the habit of intake of alcohol, $46.2 \%$ had squamous cell carcinoma and $16.2 \%$ of those without the habit had squamous cell carcinoma. This difference in proportion is statistically significant with Fisher's Exact Test (p value- 0.04).

\section{CONCLUSION}

Based on the present study, it is concluded that commonest cytomorphological subtype of lung cancer is adenocarcinoma and lung carcinoma that shows a male preponderance with male: female ratio of 15: 1 and CT-guided FNA can be used as a first line investigation in cases of lung lesions, so that thoracotomy for diagnostic purposes can be avoided.

\section{ACKNOWLEDGEMENTS}

I express my heartfelt thanks and gratitude to Dr. Sankar S, Head of the Department, Department of Pathology,
Government Medical College, Kottayam and my guide Dr. Priya PV for their support and help. Special thanks to Dr. Bobby for his concern and support through these years.

\section{REFERENCES}

[1] Gangopadhyay M, Chakrabarti I, Ghosh N, et al. Computed tomography guided fine needle aspiration cytology of mass lesions of lung: our experience. Indian J Med Paediatr Oncol 2011;32(4):192-6.

[2] Piplani S, Mannan R, Lalit M, et al. Cytologic-radiologic correlation using transthoracic CT-guided FNA for lung and mediastinal masses: our experience. J Analytical Cellular Pathology Articles ID 343461, 2014;2014:6.

[3] Modi MB, Rathva MR, Shah NR, et al. Role of FNAC in lung carcinoma and its histo-cytological correlation. J Lung Pulm Respir Res 2016;3(4):90.

[4] Mondal SK, Nag D, Das R, et al. Computed tomogram guided fine-needle aspiration cytology of lung mass with histological correlation: a study in Eastern India. South Asian J Cancer 2013;2(1):14-8.

[5] Kalhan S, Sharma P, Sharma S, et al. Evaluation of precision of guidance techniques in image guided fine needle aspiration cytology of thoracic mass lesions. J Cytol 2012;29(1):6-10. 